\title{
Exercise Training in Patients With Chronic Respiratory Failure Due to Kyphoscoliosis: A Randomized Controlled Trial
}

\author{
Pilar Cejudo MD PhD, Isabel López-Márquez MD PhD, José Luis López-Campos MD PhD, \\ Eduardo Márquez MD PhD, Francisco de la Vega MD PhD, \\ Emilia Barrot MD PhD, and Francisco Ortega MD PhD
}

\begin{abstract}
BACKGROUND: Research has provided evidence for the safety, feasibility, and efficacy of exercise training in patients with COPD. However, little is known about the impact of exercise training in patients with chronic respiratory failure due to kyphoscoliosis. We evaluated the effect of an exercise training program on exercise capacity, muscle strength, dyspnea, and quality-of-life indices in subjects with chronic respiratory failure due to kyphoscoliosis. METHODS: The 34 subjects were clinically stable, had been receiving nighttime home mechanical ventilation for $\geq 6$ months, and were randomly assigned to the exercise group $(n=17)$ or the control group $(n=17)$. The exercise group conducted cycle and strength training on 3 non-consecutive days per week for 12 weeks. We measured pulmonary function, exercise capacity, peripheral muscle strength, dyspnea scores, and quality of life. RESULTS: Statistical analysis was carried out on the data from 16 subjects in the exercise group and in $\mathbf{1 1}$ subjects in the control group. Three of the lung-function parameters in the exercise group significantly changed: $\mathrm{P}_{\mathrm{aCO}}(P=.04)$, inspiratory pressure $(P=.03)$, and expiratory pressure $(P=.04)$; and endurance time $(P=.002)$ and shuttle walk distance $(P=.001)$ increased significantly. The exercise group had significantly greater improvements in peripheral muscle strength, dyspnea, and quality of life. CONCLUSIONS: In patients with chronic respiratory failure due to kyphoscoliosis, exercise training improved exercise capacity, peripheral muscle strength, dyspnea, and quality of life. (Deutschen Register Klinischer Studien DRKS00000443) Key words: chronic respiratory failure; exercise training; kyphoscoliosis; peripheral muscle strength; quality of life; dyspnea; endurance capacity; pulmonary rehabilitation. [Respir Care 2014;59(3):375-382. (C) 2014 Daedalus Enterprises]
\end{abstract}

\section{Introduction}

Patients with severe kyphoscoliosis (KS) are at risk of developing respiratory failure, mainly due to changes in

\footnotetext{
The authors are affiliated with Unidad Médico-Quirúrgica de Enfermedades Respiratorias, Hospital Universitario Virgen del Rocío, Sevilla, Spain, with the exception of Dr de la Vega, who is affiliated with the Respiratory Department, Hospital Universitario de Valme, Sevilla, Spain.

The authors have disclosed no conflicts of interest. This study was partly supported by a grant from Asociación de Neumología y Cirugía Torácica del Sur (NEUMOSUR).

Correspondence: Pilar Cejudo MD PhD, Unidad Médico-Quirúrgica de Enfermedades Respiratorias, Hospital Universitario Virgen del Rocío, Avenida Manuel Siurot s/n, Sevilla, Spain, 41013. E-mail: mariap. cejudo.sspa@juntadeandalucia.es.
}

DOI: $10.4187 /$ respcare. 02484 the mechanical properties of the rib cage and reduced lung compliance. The magnitude of the lung restriction seems to be related to the severity of the deformity. ${ }^{1}$

Patients with KS usually show oxyhemoglobin desaturation during exercise, ${ }^{2}$ which is associated with impaired exercise capacity and disabling dyspnea. ${ }^{3}$ Several factors contribute to reduced exercise capacity in patients with KS. Hamilton et al (1995) found a significant association between peripheral muscle strength and exercise parameters in subjects with chronic respiratory diseases, including KS. ${ }^{4}$ Swallow et al (2009) found quadriceps dysfunction in patients with advanced KS. ${ }^{5}$

When KS is complicated by chronic respiratory failure, the prognosis gets worse. However, survival may be improved with noninvasive ventilation, which enhances gas exchange efficiency and alleviates alveolar hypoventilation. ${ }^{6}$ Unfortunately, both exercise limitation and dyspnea 
usually become persistent and impair health-related quality of life (HRQL). ${ }^{7}$

In patients with COPD, exercise training is recognized as an evidence-based treatment in improving exercise capacity, muscle strength, dyspnea, and HRQL. ${ }^{8}$ Recently, significant benefits from a 24-week pulmonary rehabilitation program were reported in a heterogeneous group of patients with restrictive lung diseases, some with KS. ${ }^{9}$ However, less is known about the impact of exercise training in patients with chronic respiratory failure due to KS (KS-CRF). In patients with KS-CRF we investigated an exercise program that included strength and endurance training.

\section{Methods}

This randomized controlled trial was approved by the institutional review board of, and conducted at, Hospital Universitario Virgen del Rocío, Sevilla, Spain. All subjects gave written informed consent before enrollment. We enrolled 34 KS-CRF patients: 16 males, 18 females, mean age $62.5 \pm 9.5$ years. The etiology of KS was idiopathic in 15 subjects $(45.8 \%)$, Pott disease in 11 subjects $(33.3 \%)$, post-polio in 3 subjects $(8.3 \%)$, post-traumatic in 3 subjects $(8.3 \%)$, and skeletal malformation in 2 subjects $(4.2 \%)$. We included adults with KS-CRF, receiving nighttime home mechanical ventilation for $\geq 6$ months, and who had been clinically stable for $\geq 3$ months. Our definition of CRF included $\mathrm{P}_{\mathrm{aO}_{2}}<60 \mathrm{~mm} \mathrm{Hg}$ and/or $\mathrm{P}_{\mathrm{aCO}_{2}}$ $>45 \mathrm{~mm} \mathrm{Hg}$. We excluded patients who had any contraindication to any study procedure or were unable to perform any of the study tests (eg, uncontrolled heart disease or acute pulmonary disease). After baseline assessments the subjects were randomly allocated to the exercise group or the control group, using a computer-generated randomization list. Seventeen subjects were allocated to each group. The sequence was concealed until interventions were assigned. All the subjects used noninvasive ventilation (BIPAP, Respironics, Murrysville, Pennsylvania) and took their usual medications. The control subjects were only scheduled for the baseline and final evaluation visits.

\section{Training Protocol}

The exercise-group subjects trained 3 non-consecutive days per week for 12 weeks, in our hospital's pulmonary rehabilitation unit. The exercise sessions were supervised, lasted approximately $60 \mathrm{~min}$, and included a 10 -min period of warm-up and stretching. The sessions included a 30-min period of leg exercise on a calibrated ergometer cycle (ZX1, Kettler Sport, Ense-Parsit, Germany) and 5 weight-lifting exercises for the major upper and lower body muscles. The target training intensity was $70 \%$ of the baseline peak work load. The strength-training program was

\section{QUICK LOOK}

\section{Current knowledge}

Exercise training in a pulmonary rehabilitation program improves quality of life in patients with COPD. The impact of exercise training on patients with kyphoscoliosis and restrictive lung disease is not well described.

\section{What this paper contributes to our knowledge}

In patients with chronic respiratory failure due to kyphoscoliosis, exercise training improved exercise capacity, peripheral muscle strength, dyspnea, and quality of life.

performed as previously described. ${ }^{10}$ The subjects were administered supplemental oxygen during training, if necessary to maintain oxygen saturation above $90 \%$.

\section{Measurement Protocol}

The subjects were evaluated at baseline and after 12 weeks of training. The baseline and post-intervention tests and assessments were performed under similar conditions. Each subject underwent pulmonary function tests, shuttle walk test, endurance test, maximal cycle exercise test, peripheral muscle strength tests; HRQL assessment, and dyspnea assessment. Our primary outcomes were changes in endurance and shuttle walk test results.

\section{Pulmonary Function Tests}

Spirometry (Masterlab, Erich Jaeger, Friedberg, Germany) was per the Sociedad Española de Neumología y Cirugía Torácica (SEPAR) ${ }^{11}$ and American Thoracic Society $^{12}$ recommendations.

\section{Exercise Testing}

Cardiopulmonary exercise testing was performed with a cycle ergometer (Ergomed, Collins Respiratory, Braintree, Massachusetts) as previously described, ${ }^{13}$ and according to the international standards. ${ }^{14}$ After 2 days a cycling test was performed at a constant work load of $70 \%$ of the maximum achieved during the initial cardiopulmonary exercise test, to obtain the endurance time. Post-endurancetest dyspnea was assessed with the modified Borg scale. ${ }^{15}$ Following a 2-hour rest, the shuttle walk test was conducted, as described by Singh et al, ${ }^{16}$ and we recorded the maximum level reached and the distance covered.

\section{Respiratory and Peripheral Muscle Strength}

Maximum inspiratory pressure, measured at the mouth, starting from residual volume, and maximum expiratory 
pressure, measured at the mouth, starting from total lung capacity, were measured (163, SibelMed, Barcelona, Spain) and analyzed with the reference from Morales et al. ${ }^{17}$ One-repetition maximum tests were used for measuring peripheral muscle strength. ${ }^{18}$ This type of test measures the maximum amount of weight that can be lifted in a single movement, using a multi-station weightlifting machine (Fitness Classic Centre, Kettler, Postfach, Germany). Five simple exercises (chest pull, butterfly, shoulder press, leg extension and leg curls) engaging the largest muscles of the lower and upper limbs were selected.

\section{Dyspnea}

Baseline dyspnea was measured with the Baseline Dyspnea Index/Transitional Dyspnea Index, ${ }^{19}$ and the modified Medical Research Council dyspnea scale. ${ }^{20}$ The Baseline Dyspnea Index/Transitional Dyspnea Index has 3 domains (functional impairment, magnitude of task, and magnitude of effort) that are graded from -3 to 3 , where scores in the range -1 to -3 signify deterioration, 0 signifies no change, and scores in the range 1 to 3 signify improvement. A 1-unit is thought to imply clinical importance. ${ }^{21}$ The modified Medical Research Council dyspnea scale is a set of 5 statements about dyspnea. The subject is asked to select the statement that most closely applies.

\section{Health-Related Quality of Life}

The Chronic Respiratory Disease Questionnaire, Spanish validated version, ${ }^{22,23}$ was used to assess HRQL. This instrument has 4 domains (dyspnea, fatigue, emotional function, and mastery), each of which is measured on a 7-point scale, and a score of 7 indicates no health impairment; consequently, the higher the score, the better the quality of life. A change of 0.5 unit is considered the minimum clinically important change.

\section{Statistical Analysis}

The trial was designed to determine the effects of exercise training on exercise, muscle strength, dyspnea, and quality-of-life parameters. The sample size was calculated based on the work load increase in the cardiopulmonary exercise test in a prior study. ${ }^{10}$ Considering a 10-Watt increase and \pm 5 Watts as the standard deviation, a sample size of 30 subjects ( 15 per group) was necessary to detect a significant difference between the groups, with a power of $90 \%$ and an $\alpha$ error of .05, using a 2-tailed test. Assuming 15\% lost to follow-up, we planned to enroll 34 subjects. Data are presented as mean \pm SD. The Kolmogorov-Smirnov test revealed skewed distribution in all the continuous variables, so nonparametric statistical procedures were used for the data analysis. Within-group
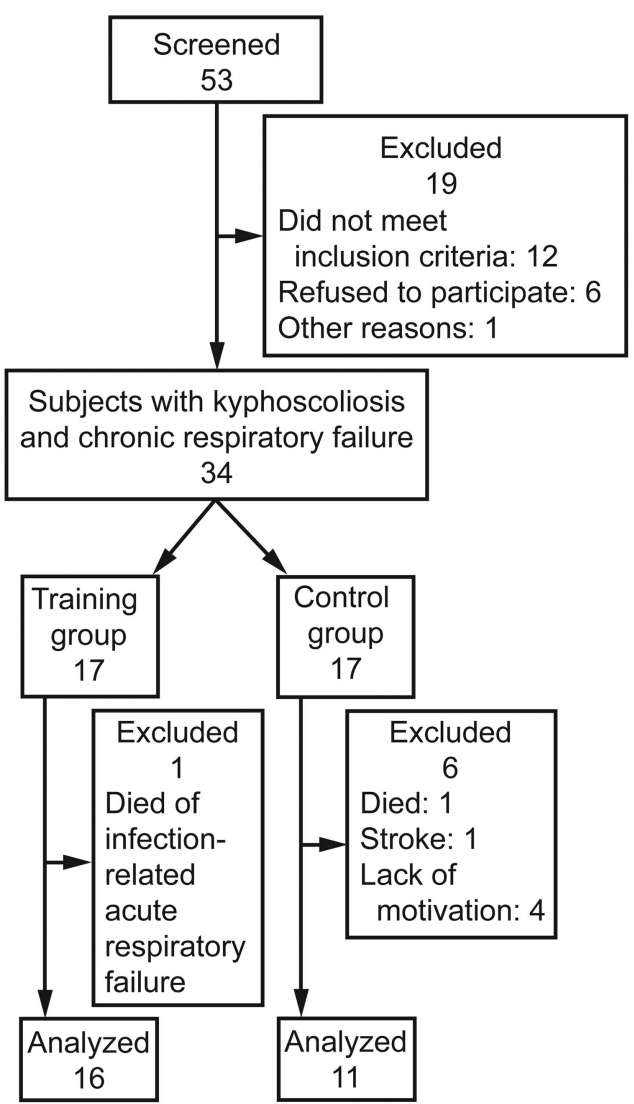

Fig. 1. Flow chart.

comparisons of outcome measures were done with the Wilcoxon test. We used the Mann-Whitney U test to compare changes between groups. We used statistics software (SPSS 14.0, SPSS, Chicago, Illinois) for all calculations. Differences were considered statistically significant when the 2-tailed $P$ was $<.05$.

\section{Results}

Figure 1 shows the flow chart. A total of $34 \mathrm{KS}$-CRF subjects were initially included. The subjects exhibited a severe deformity: range $90-130^{\circ}$ (26 subjects) of scoliosis, and $92-125^{\circ}$ (34 subjects) of kyphosis. In the exercise group $(n=17)$ one subject died of infection-related acute respiratory failure. In the control group $(n=17)$ one subject died of acute respiratory failure, one subject had a stroke, and 4 subjects dropped out due to lack of motivation. Therefore, statistical analysis was carried out on the data from 16 subjects in the exercise group and 11 subjects in the control group. None of the exercise subjects had any important complications during or from the exercise program, and they completed $82 \%$ of the training sessions. Table 1 presents the baseline characteristics. There were no significant differences between the groups in any of the 
Table 1. Baseline Characteristics

\begin{tabular}{|c|c|c|c|}
\hline & $\begin{array}{c}\text { Exercise } \\
\text { Group } \\
(n=16)\end{array}$ & $\begin{array}{c}\text { Control } \\
\text { Group } \\
(n=11)\end{array}$ & $P$ \\
\hline Male/female, no. & $7 / 9$ & $6 / 5$ & .80 \\
\hline Age, y & $61.1 \pm 9.0$ & $63.9 \pm 9.1$ & .39 \\
\hline Months on home mechanical ventilation & $18.4 \pm 5$ & $17.8 \pm 3$ & .50 \\
\hline FVC, $\%$ predicted & $31.8 \pm 9.6$ & $35.7 \pm 12.0$ & .36 \\
\hline $\mathrm{FEV}_{1}, \%$ predicted & $29.3 \pm 9.6$ & $30.7 \pm 9.6$ & .87 \\
\hline $\mathrm{FEV}_{1} / \mathrm{FVC}, \%$ & $75.8 \pm 12.0$ & $71.6 \pm 14.4$ & .26 \\
\hline Functional residual capacity, $\%$ predicted & $53.9 \pm 21.4$ & $54.2 \pm 16.7$ & .64 \\
\hline Residual volume, \% predicted & $59.4 \pm 14.8$ & $59.7 \pm 15.9$ & .89 \\
\hline Total lung capacity, $\%$ predicted & $40.8 \pm 9.6$ & $43.4 \pm 15.0$ & .25 \\
\hline $\mathrm{P}_{\mathrm{aO}_{2}}, \mathrm{~mm} \mathrm{Hg}$ & $64.9 \pm 9.2$ & $64.1 \pm 18.0$ & .74 \\
\hline $\mathrm{P}_{\mathrm{aCO}_{2}}, \mathrm{~mm} \mathrm{Hg}$ & $48.4 \pm 4.6$ & $45.1 \pm 5.6$ & .35 \\
\hline Maximum inspiratory pressure, $\mathrm{cm} \mathrm{H}_{2} \mathrm{O}$ & $37 \pm 10.4$ & $36.4 \pm 9.5$ & .83 \\
\hline Maximum inspiratory pressure, $\%$ predicted & $38 \pm 7$ & $36.9 \pm 6$ & \\
\hline Maximum expiratory pressure, $\mathrm{cm}_{2} \mathrm{O}$ & $75.3 \pm 23.1$ & $86 \pm 35.4$ & .64 \\
\hline Maximum expiratory pressure, $\%$ predicted & $48 \pm 12$ & $54 \pm 14$ & \\
\hline
\end{tabular}

$\overline{\text { Values are mean } \pm \text { SD }}$ unless otherwise indicated.

Table 2. Exercise Capacity Before and After Training

\begin{tabular}{|c|c|c|c|c|c|c|c|}
\hline & \multicolumn{3}{|c|}{ Exercise Group ( $n=16)$} & \multicolumn{3}{|c|}{ Control Group $(n=11)$} & \multirow{2}{*}{$\begin{array}{c}P \text { for } \\
\text { Inter-Group } \\
\text { Comparison } \dagger\end{array}$} \\
\hline & Baseline & Post-intervention & $P^{*}$ & Baseline & Post-intervention & $P^{*}$ & \\
\hline Maximum $\dot{\mathrm{V}}_{\mathrm{O}_{2}}, \%$ predicted & $50.5 \pm 12.2$ & $52.4 \pm 18.3$ & .97 & $46.7 \pm 12.2$ & $47.2 \pm 12.6$ & .63 & .80 \\
\hline Maximum work, $\%$ predicted & $20.6 \pm 15.9$ & $26.8 \pm 20.3$ & .16 & $17.4 \pm 16.4$ & $19.6 \pm 22.8$ & .12 & .30 \\
\hline Shuttle walk distance, $\mathrm{m}$ & $187.5 \pm 116.7$ & $259.6 \pm 118.1$ & .001 & $229.3 \pm 98.4$ & $255.0 \pm 125.5$ & .08 & .06 \\
\hline Shuttle walk test level & $4.4 \pm 1.8$ & $5.5 \pm 1.6$ & .007 & $5.3 \pm 1.4$ & $5.2 \pm 1.9$ & .89 & .07 \\
\hline Dyspnea score during shuttle walk test & $8.7 \pm 0.8$ & $8.1 \pm 1.9$ & .80 & $8.7 \pm 0.9$ & $8.3 \pm 1.2$ & .90 & .90 \\
\hline Endurance cycle time, min & $10.7 \pm 15.4$ & $22.7 \pm 20.3$ & .002 & $11.7 \pm 18.9$ & $18.5 \pm 22.8$ & .40 & .41 \\
\hline Dyspnea score during endurance test & $8.0 \pm 1.9$ & $6.6 \pm 2.9$ & .70 & $7.5 \pm 2.7$ & $7.4 \pm 2.0$ & .80 & .73 \\
\hline $\begin{array}{l}\text { Values are mean } \pm \text { SD. } \\
* \text { Via Wilcoxon test. } \\
\dagger \text { Via Mann-Whitney U test. } \\
\dot{\mathrm{V}}_{\mathrm{O}_{2}}=\text { oxygen uptake }\end{array}$ & & & & & & & \\
\hline
\end{tabular}

baseline measurements. All the subjects had severe pulmonary function impairment, and the only variable that significantly changed after the study intervention was $\mathrm{P}_{\mathrm{aCO}_{2}}$, which decreased from $48.4 \pm 4.6 \mathrm{~mm} \mathrm{Hg}$ to $47.2 \pm 5.1 \mathrm{~mm} \mathrm{Hg}(P=.04)$.

\section{Changes in Exercise Capacity}

Table 2 lists the exercise capacity outcomes. There were no significant changes in maximum $\dot{\mathrm{V}}_{\mathrm{O}_{2}}$ or maximum work in either group after the exercise program. Similarly, the increases in maximum $\dot{\mathrm{V}}_{\mathrm{O}_{2}}$ or maximum work were not significantly different between the groups.

The mean distance walked in the shuttle walk test increased significantly in the exercise group (mean increase
$67.2 \mathrm{~m}, P=.001$ ) but not in the control group (mean increase $23.3 \mathrm{~m}, P=.08$ ). The greatest increase was in cycle endurance time in the exercise-group subjects (mean increase $12.2 \mathrm{~min}, P=.002$, see Table 2). Despite this, the changes were not significantly different between the groups $(P=.41)$. There was no significant post-intervention change in dyspnea or leg discomfort in either group.

\section{Changes in Respiratory and Peripheral Muscle Strength}

Maximum inspiratory pressure and maximum expiratory pressure increased significantly, from $38 \pm 7 \%$ to $41.3 \pm 8 \%(P=.03)$, and from $48 \pm 12 \%$ to $52.3 \pm 6 \%$ $(P=.04)$, respectively. Figure 2 and Table 3 show the 


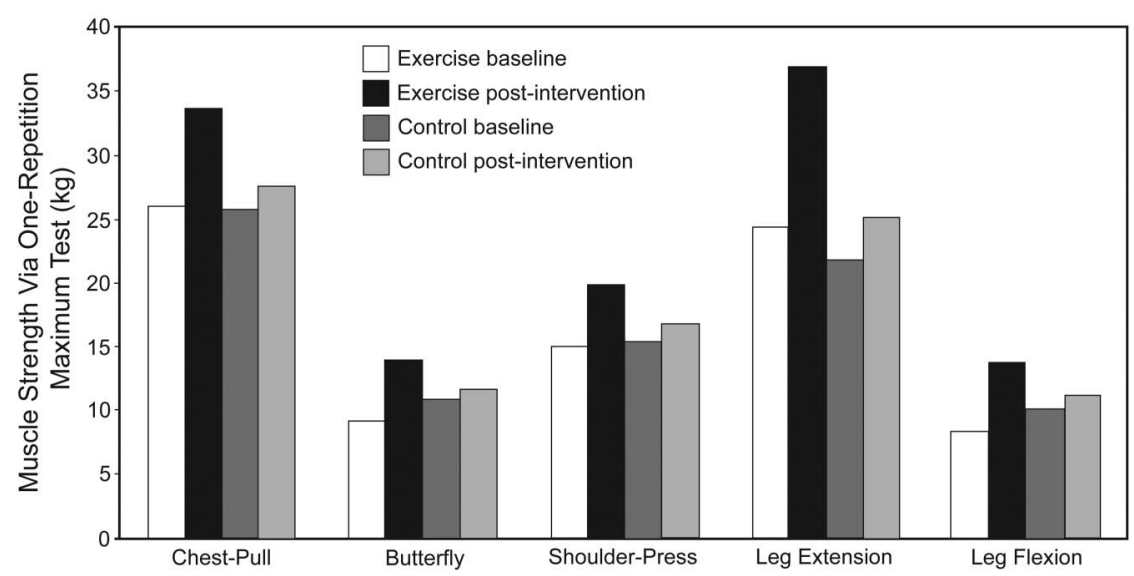

Fig. 2. Muscle strength at baseline and after a 12-week exercise training program.

Table 3. Peripheral Muscle Strength Before and After Training

\begin{tabular}{|c|c|c|c|c|c|c|c|}
\hline & \multicolumn{3}{|c|}{ Exercise Group, $\operatorname{kg}(n=16)$} & \multicolumn{3}{|c|}{ Control Group, $\mathrm{kg}(n=11)$} & \multirow{2}{*}{$\begin{array}{c}P \text { for } \\
\text { Inter-Group } \\
\text { Comparison }\end{array}$} \\
\hline & Baseline & Post-intervention & $P^{*}$ & Baseline & Post-intervention & $P^{*}$ & \\
\hline Chest pull & $26 \pm 7.5$ & $33.7 \pm 9.3 \ddagger$ & .001 & $25.7 \pm 7.6$ & $27.5 \pm 8.7$ & .042 & .01 \\
\hline Butterfly & $9.2 \pm 5.2$ & $14 \pm 8 \ddagger$ & .001 & $10.9 \pm 6.3$ & $11.7 \pm 7.4$ & .042 & .02 \\
\hline Shoulder press & $15.1 \pm 8.7$ & $19.9 \pm 10.8 \ddagger$ & .001 & $15.3 \pm 4.9$ & $16.7 \pm 6.8$ & .09 & .006 \\
\hline Leg extension & $24.4 \pm 10.7$ & $37 \pm 13.3 \ddagger$ & $<.001$ & $21.7 \pm 7.1$ & $25.1 \pm 7.9$ & .09 & .005 \\
\hline Leg flexion & $8.4 \pm 5.1$ & $13.8 \pm 4.5 \ddagger$ & .01 & $10.1 \pm 5$ & $11.2 \pm 4.5$ & .09 & .02 \\
\hline \multicolumn{8}{|c|}{$\begin{array}{l}\text { Values are mean } \pm \mathrm{SD} . \\
* \text { Via Wilcoxon test. } \\
\dagger \text { Via Mann-Whitney U test. } \\
\ddagger P<.05 \text {. }\end{array}$} \\
\hline
\end{tabular}

peripheral muscle strength outcomes. The average onerepetition maximum for all exercises increased significantly in the exercise group, and in comparison to the control group. The control group had statistically significant increases only in the chest pull and butterfly exercises.

\section{Changes in Dyspnea and HRQL}

Table 4 lists the dyspnea and quality of life outcomes. The changes were significantly different between the groups. The mean modified Medical Research Council dyspnea score decreased significantly in the exercise group, by $0.5 \pm 0.6$ units $(P=.02)$. There were meaningful improvements in all the Transitional Dyspnea Index domains: magnitude of task $1.8 \pm 1.1$ units, functional impairment $1.6 \pm 1.2$ units, magnitude of effort $1.6 \pm 1.2$ units (all $P<.05$ ). The global score of the HRQL questionnaire and 3 of 4 of its existing domains (dyspnea, fatigue, and emotional function) increased significantly in the exercise group. In the control group there was no improvement in dyspnea or HRQL.

\section{Discussion}

To our knowledge, this is the first randomized controlled trial to investigate the effects of exercise training that combined endurance and strength in subjects with KS-CRF. In support of our hypotheses, we found that exercise training improved exercise capacity, peripheral muscle strength, dyspnea, and quality of life, whereas there were no significant changes in the control group. One of the strengths of the current study is its design, which was randomized, prospective, and controlled, in contrast to previous research. ${ }^{9}$ Conversely, a limitation of the present study is the small sample size and its heterogeneity, which is explained by the difficulty in recruiting patients with a rare condition such as KS-CRF.

\section{Lung Function and Respiratory Muscle Strength}

Pulmonary rehabilitation does not directly improve lung mechanics or gas exchange. Our intervention changed only one lung function parameter: $\mathrm{P}_{\mathrm{aCO}_{2}}$. Few data are available on the effects of exercise training in patients with chronic 
Table 4. Dyspnea and Quality of Life Before and After Training

\begin{tabular}{|c|c|c|c|c|c|c|c|}
\hline & \multicolumn{3}{|c|}{ Exercise Group $(n=16)$} & \multicolumn{3}{|c|}{ Control Group $(n=11)$} & \multirow{2}{*}{$\begin{array}{c}P \text { for } \\
\text { Inter-Group } \\
\text { Comparison }\end{array}$} \\
\hline & Baseline & Post-intervention & $P^{*}$ & Baseline & Post-intervention & $P^{*}$ & \\
\hline Dyspnea score & $3.8 \pm 0.9$ & $3.2 \pm 0.8 \neq$ & .02 & $3.7 \pm 1.1$ & $3.5 \pm 1.1$ & .90 & .045 \\
\hline \multicolumn{8}{|c|}{$\begin{array}{l}\text { Baseline Dyspnea Index/Transitional Dyspnea } \\
\text { Index domain }\end{array}$} \\
\hline Magnitude of task & $1.1 \pm 0.6$ & $+1.8 \pm 1.1 \S \|$ & .02 & $1.4 \pm 0.8$ & $+0.2 \pm 0.4$ & .45 & .002 \\
\hline Functional impairment & $1.2 \pm 0.6$ & $+1.6 \pm 1.2 \S \ddagger$ & .04 & $1.6 \pm 1.2$ & $+0.2 \pm 0.4$ & .60 & .01 \\
\hline Magnitude of effort & $1.1 \pm 0.6$ & $+1.6 \pm 1.2 \S \ddagger$ & .02 & $1.5 \pm 0.8$ & $+0.1 \pm 1.2$ & .83 & .005 \\
\hline Focal score & $4.6 \pm 2.5$ & $+5.0 \pm 3.3 \S \|$ & .02 & $3.6 \pm 1.9$ & $+0.3 \pm 1.9$ & .57 & .003 \\
\hline \multicolumn{8}{|c|}{ Chronic Respiratory Disease Questionnaire domain } \\
\hline Dyspnea & $2.7 \pm 0.9$ & $3.7 \pm 0.9 \S 末$ & .003 & $2.7 \pm 0.7$ & $2.9 \pm 0.5$ & .54 & .03 \\
\hline Fatigue & $3.7 \pm 0.8$ & $4.7 \pm 1.0 \S$ & .005 & $4.1 \pm 1.3$ & $4.6 \pm 1.1$ & 64 & .01 \\
\hline Emotional function & $4.4 \pm 0.9$ & $5.1 \pm 1.0 \S 末$ & .01 & $4.6 \pm 1.4$ & $5.0 \pm 1.6$ & .09 & .01 \\
\hline Mastery & $5.0 \pm 1.2$ & $5.6 \pm 0.9$ & .09 & $4.5 \pm 1.6$ & $5.4 \pm 1.1$ & .08 & .55 \\
\hline Global & $12.1 \pm 2.0$ & $15.0 \pm 2.8 \S \ddagger$ & .005 & $12.7 \pm 2.9$ & $13.9 \pm 2.9$ & .07 & .02 \\
\hline \multicolumn{8}{|c|}{$\begin{array}{l}\text { Values are mean } \pm \mathrm{S} D . \\
* \text { Via Wilcoxon test. } \\
\dagger \text { Via Mann-Whitney } \mathrm{U} \text { test. } \\
\ddagger P<.05 \text {. } \\
\S \text { Clinically important change }(0.5 \text { point increase in Chronic Respiratory Disease Questionnaire domain score). } \\
\| P<.005 \text {. }\end{array}$} \\
\hline
\end{tabular}

respiratory failure. ${ }^{24} \mathrm{~A}$ multi-center Italian study recently investigated the impact of exercise training in COPD patients with and without chronic respiratory failure. ${ }^{25}$ After training, the subjects with chronic respiratory failure had significantly reduced mean $\mathrm{P}_{\mathrm{aCO}}(-3.3 \mathrm{~mm} \mathrm{Hg})$. The magnitude of that change is more than double that observed in our study $(-1.2 \mathrm{~mm} \mathrm{Hg})$, but it was similarly significant. In subjects with $\mathrm{KS}$, previous studies have found an inverse correlation between $\mathrm{P}_{\mathrm{aCO}}$ and maximum inspiratory pressure,${ }^{26}$ indicating that impairment of inspiratory muscle function may lead to respiratory failure. The improved inspiratory muscle function after exercise training is probably associated with improved thoracic mobility. Additional improvements in dynamic ventilatory mechanics may reduce microatelectasis, resulting in increased elastic recoil of the lung and improved $\mathrm{P}_{\mathrm{aCO}}$. Our finding that respiratory muscle strength consistently increased suggests that not only the muscles of the shoulder girdle, which contribute to pulmonary ventilation, but also the inspiratory muscles were overloaded sufficiently during the course of upper-extremity training.

\section{Exercise Tolerance}

Despite appropriate medical treatment and home mechanical ventilation, our subjects were severely impaired. We found that exercise training did not significantly improve maximum $\dot{\mathrm{V}}_{\mathrm{O}_{2}}$ or maximum work, but this result was expected, given our subjects' high degree of respiratory impairment. Intriguingly, maximum work increased by $30 \%$ in the exercise group. The magnitude of this treatment effect is higher than the reported mean increase $(18 \%)$ after COPD rehabilitation. ${ }^{27}$ Lower limb strength training and cycling may account for this beneficial effect.

Another main finding of our trial is that cycling endurance time and shuttle walk test level and distance improved significantly in the exercise group. These results are of interest, since endurance (rather than strength) is important for activities of daily living. Exercise training was associated with a $112 \%$ improvement in cycle endurance. The magnitude of that change is similar to the change reported in COPD patients, who generally show greater improvements in constant work rate tests. ${ }^{27}$ It is noteworthy that the shuttle walk test has been validated to be sensitive to assess functional capacity in patients with $\mathrm{KS}^{28}$ Interestingly, the mean shuttle walk distance increase was $67.2 \mathrm{~m}$ in the exercise group, which exceeds the $47.5 \mathrm{~m}$ that is considered to be the minimum clinically important difference after pulmonary rehabilitation. ${ }^{29}$ Part of these increases might account for a learning effect, given the smaller yet nonsignificant increases also observed in the control group, for both tests.

\section{Peripheral Muscle Strength}

Abnormalities of the peripheral muscles play a crucial role in exercise intolerance in patients with chronic respiratory disease. ${ }^{4,30}$ However, peripheral muscle strength is not routinely measured in patients with KS-CRF. Our subjects had low strength measurements, which is in line with 
the results of a recent study that provided important data documenting weakness and fiber-type changes in the quadriceps muscle in patients with scoliosis. ${ }^{5}$ These data support the rationale for muscle training in patients with KS-CRF.

In our KS-CRF subjects the magnitude of changes in peripheral muscle strength ranged between $29.6 \%$ and $64.2 \%$, and were significantly greater in the exercise group. This improvement is consistent with a growing body of research showing that exercise training improves peripheral muscle strength in patients with restrictive lung diseases. ${ }^{9,31}$

\section{Dyspnea and HRQL}

Our results demonstrate that exercise training improves dyspnea. Further studies are needed to explore factors contributing to dyspnea in KS-CRF patients. We previously found that both respiratory muscle strength and peripheral muscle strength affect dyspnea and exercise capacity in KS-CRF subjects. ${ }^{32}$ It is therefore reasonable to assume that improved peripheral muscle strength contributed to the improved patient perception of breathing. A change of 1 unit in the Transitional Dyspnea Index is considered the minimum clinically important difference. ${ }^{21}$ The improvement in Baseline Dyspnea Index/Transitional Dyspnea Index and in all 3 domains of the Transitional Dyspnea Index in the exercise group can thus be considered a clinically important change.

Peripheral muscle strength, dyspnea, and exercise capacity have independent effects on HRQL in KS-CRF patients. ${ }^{33}$ Our subjects had impaired HRQL, with lower scores on the dyspnea and fatigue dimensions. An important finding of our trial was that exercise training improved the overall HRQL score. In addition, there were significant improvements in 3 of the 4 domains of the Chronic Respiratory Disease Questionnaire, that exceeded the minimum important difference of 0.5 point, ${ }^{34}$ and significantly surpassed the changes in the control group. There was no significant post-intervention change in the mastery domain score, which may be due to the fact that our subjects were stable and under optimal medical therapy.

\section{Limitations}

Our small sample size and its heterogeneity may account for the lack of significant differences in exercise capacity between the training and control groups. Evaluating long-term benefits might have provided additional valuable information on that issue. Also, the control group didn't have the same number of visits as the exercise group, which may explain the substantial drop-out rate in the control group.

\section{Conclusions}

Collectively, our results demonstrate the safety, feasibility, and efficacy of exercise training in patients with KS-CRF. The benefits we obtained are in line with those previously reported in observational studies, ${ }^{9,35}$ despite that our subjects were more severely ill. Our exercise intervention consisted of a complete simultaneous training for both strength and endurance, which improved exercise capacity, muscle strength, dyspnea, and HRQL. This approach may help define the optimal content of pulmonary rehabilitation programs for KS-CRF patients. In summary, our findings suggest that exercise training should be recommended to KS-CRF patients receiving nighttime home mechanical ventilation.

\section{REFERENCES}

1. Bergofsky EH, Turino GM, Fishman AP. Cardiorespiratory failure in kyphoscoliosis. Medicine (Baltimore) 1959;38:263-317.

2. Kearon C, Viviani CB, Kirkley A, Kilian KJ. Factors determining pulmonary function in adolescents idiophatic thoracic scoliosis. Am Rev Respir Dis 1993;148(2):288-294.

3. O'Donnell DE, Hong HH, Webb KA. Respiratory sensation during chest wall restriction and dead space loading in exercising men. J Appl Physiol 2000;88(5):1859-1869.

4. Hamilton AL, Killian KJ, Summers E, Jones NL. Muscle strength, symptom intensity, and exercise capacity in patients with cardiopulmonary disorders. Am J Respir Crit Care Med 1995;152(6 Pt 1): 2021-2031.

5. Swallow EB, Barreiro E, Gosker H, Sathyapala SA, Sanchez F, Hopkinson NS, et al. ENIGMA in COPD project. Quadriceps muscle strength in scoliosis. Eur Respir J 2009;34(6):1429-1435.

6. Hill NS, Eveloff SE, Carlisle CC, Goff SG. Efficacy of nocturnal ventilations in patients with restrictive thoracic disease. Am Rev Respir Dis 1992;145(2 Pt 1):365-371.

7. Gonzalez C, Ferris G, Diaz J, Fontana I, Nuñez J, Marín J. Kyphoscoliotic ventilatory insufficiency: effects of long-term intermittent positive-pressure ventilation. Chest 2003;124(3):857-862.

8. Nici L, Donner C, Wouters E, Zuwallack R, Ambrosino N, Bourbeau $\mathrm{J}$, et al; American Thoracic Society/European Respiratory Society. Statement on pulmonary rehabilitation. Am J Respir Crit Care Med 2006;173(12):1390-1413.

9. Salhi B, Troosters T. Behaegel M, Joos G, Derom E. Effects of pulmonary rehabilitation in patients with restrictive lung diseases Chest 2010;137(2):273-279.

10. Ortega F, Toral J, Cejudo P, Villagomez R, Sanchez H, Castillo J. Comparison of effects of strength and endurance training in patients with chronic obstructive pulmonary disease. Am J Respir Crit Care Med 2002;166(5):669-674.

11. SEPAR. Normative of forced spirometry. Barcelona: Ed Doyma; 1985:1-19.

12. Miller MR, Hankinson J, Brusasco V, Burgos F, Casaburi R, Coates A, et al. Standardisation of spirometry. Eur Respir J 2005; 26(2):319-338.

13. Ortega F, Montemayor T, Sanchez A, Cabello F, Castillo J. Role of cardiopulmonary exercise testing and the criteria used to determine disability in patients with severe chronic obstructive pulmonary disease. Am J Respir Crit Care Med 1994;150(3):747-751.

14. American Thoracic Society, American College of Chest Physicians. ATS/ACCP statement on cardiopulmonary exercise testing. Am J Respir Crit Care Med 2003;167(2):211-277. 


\section{Exercise Training in Patients With Kyphoscoliosis}

15. Altose MD. Assessment and management of breathlessness. Chest 1985;88 (2 Suppl):77S-83S.

16. Singh SJ, Morgan MD, Scott S, Walters D, Hardman AE. Development of a shuttle walking test of disability in patients with chronic airways obstruction. Thorax 1992;47(12):1019-1024.

17. Morales P, Sanchis J, Cordero PJ, Díez JL. Maximum static respiratory pressures in adults. The reference values for a Mediterranean Caucasian population. Arch Bronconeumol 1997;33(5):213-219.

18. Lillegard WA, Terrio JD. Appropriate strength training. Med Clin North Am 1994;78(2):457-477.

19. Mahler DA, Weinberg DH, Wells CK, Feinstein AR. The measurement of dyspnea. Contents, interobserver agreement, and physiologic correlates of two new clinical indexes. Chest 1984;85(6):751758.

20. Sweer L, Zwillich CW. Dyspnea in the patient with chronic obstructive pulmonary disease. Etiology and management. Clin Chest Med 1990;11(3):417-445.

21. Witek TJ Jr., Mahler DA. Minimal important difference of the transition dyspnea index in a multinational clinical trial. Eur Respir $\mathrm{J}$ 2003;21(2):267-272.

22. Guyatt GH, Berman LB, Townsend M, Pugsley SO, Chambers LW. A measure of quality of life for clinical trials in chronic lung disease. Thorax 1987;42(10):733-778.

23. Güell R, Casan P, Sangenis M, Santis J, Morante F, Borras JM, et al. [The Spanish translation and evaluation of a quality-of-life questionnaire in patients with chronic obstructive pulmonary disease]. Arch Bronconeumol 1995;31(5):202-210.

24. Decramer M. Treatment of chronic respiratory failure: lung volume reduction surgery versus rehabilitation [review]. Eur Respir J Suppl 2003;47S-56S.

25. Carone M, Patessio A, Ambrosino N, Baiardi P, Balbi B, Balzano G, et al. Efficacy of pulmonary rehabilitation in chronic respiratory failure (CRF) due to chronic obstructive pulmonary disease (COPD): The Maugeri Study. Respir Med 2007;101(12):2447-2453.
26. Lisboa C, Moreno R, Fava M, Ferreti R, Cruz E. Inspiratory muscle function in patients with severe kyphoscoliosis. Am Rev Respir Dis 1985;132(2):48-52.

27. Troosters T, Casaburi R, Gosselink R, Decramer M. Pulmonary rehabilitation in chronic obstructive pulmonary disease. Am J Respir Crit Care Med 2005;172(1):19-38

28. López-Campos JL, Cejudo P, Ortega F, López-Márquez I, MárquezMartín E, Capote F, et al. Shuttle walking versus maximal cycle testing: Clinical correlates in patients with kyphoscoliosis. Respir Physiol Neurobiol 2008;160(3):334-340.

29. Singh SJ, Jones PW, Evans R, Morgan MD. Minimum clinically important improvement for the incremental shuttle walking test. Thorax 2008;63(9):775-777.

30. Dourado VZ, Antunes LC, Tanni SE, de Pavia SA, Padovani CR, Godoy I. Relationship of upper-limb and thoracic muscle strength to 6-min walk distance in COPD patients. Chest 2006;129(3):551557.

31. Holland A, Hill C. Physical training for interstitial lung disease. Cochrane Database Syst Rev 2008;(4):CD006322.

32. Lopez-Campos JL, Lopez I, Cejudo P, Ortega F, Barrot E, Sanchez $\mathrm{H}$, et al. Contribution of peripheral muscle strength to the exercise capacity and dyspnea in patients with hypercapnic respiratory failure due to kyphoscoliosis. Eur Respir J 2006;28(Suppl):370S.

33. Cejudo P, López-Márquez I, Lopez-Campos JL, Ortega F, Bernal CC, Márquez E, et al. Factors associated with quality of life in patients with chronic respiratory failure due to kyphoscoliosis. Disabil Rehabil 2009;31(11):928-934.

34. Jaeschke R, Singer J, Guyatt GH. Measurement of health status: ascertaining the minimal clinically important difference. Control Clin Trial 1989;10(4):407-415.

35. Naji NA, Connor MC, Donnelly SC, McDonnell TJ. Effectiveness of pulmonary rehabilitation in restrictive lung disease. J Cardiopulm Rehabil 2006;26(4):237-243. 